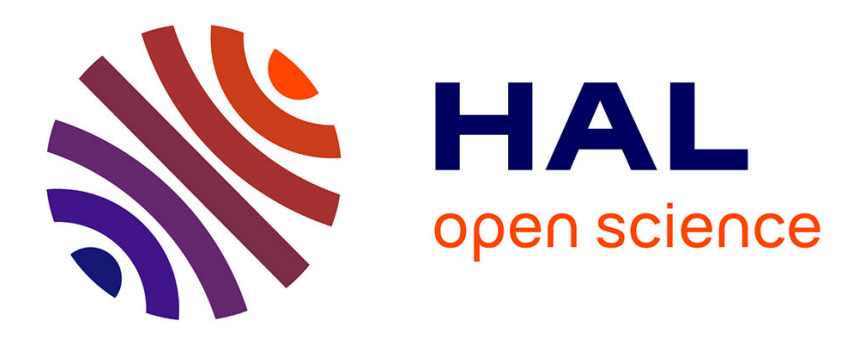

\title{
The sulfur content of volcanic gases on Mars
}

Fabrice Gaillard, Bruno Scaillet

\section{To cite this version:}

Fabrice Gaillard, Bruno Scaillet. The sulfur content of volcanic gases on Mars. Earth and Planetary

Science Letters, 2009, 279 (1-2), pp.34-43. 10.1016/j.epsl.2008.12.028 . insu-00361741

\section{HAL Id: insu-00361741 \\ https://hal-insu.archives-ouvertes.fr/insu-00361741}

Submitted on 16 Feb 2009

HAL is a multi-disciplinary open access archive for the deposit and dissemination of scientific research documents, whether they are published or not. The documents may come from teaching and research institutions in France or abroad, or from public or private research centers.
L'archive ouverte pluridisciplinaire HAL, est destinée au dépôt et à la diffusion de documents scientifiques de niveau recherche, publiés ou non, émanant des établissements d'enseignement et de recherche français ou étrangers, des laboratoires publics ou privés. 


\title{
The sulfur content of volcanic gases on Mars
}

\author{
Fabrice Gaillard ${ }^{\text {a }}$ and Bruno Scaillet ${ }^{1,}$ a \\ ${ }^{a}$ CNRS/INSU, Université d'Orléans, Université François Rabelais-Tours, Institut des \\ Sciences de la Terre d'Orléans-UMR 6113-Campus Géosciences, 1A, rue de la Férollerie, \\ 41071 Orléans Cedex 2, France
}

\begin{abstract}
Both high sulfur contents of the martian regolith and lack of detection of extensive carbonate deposits suggest that the latest geological events that shaped the landscapes of Mars were dominated by acidic waters possibly related to appreciable $\mathrm{SO}_{2}$ concentrations in the atmosphere. On the basis of fundamental thermochemical principles, we model here the likely sulfur contents of (1) the martian and terrestrial mantles and (2) the volcanic gases delivered by the corresponding basaltic magmas. We find that the martian mantle contains at least 3-4 times as much sulfur as its terrestrial counterpart, yielding basaltic melts richer in sulfur than those on Earth. Such an S-enrichment is explained by contrasted redox conditions prevailing during magma ocean equilibration, which lead to distinct iron contents of the martian and terrestrial mantles and of their basaltic derivatives. Calculated volcanic gas compositions in equilibrium with a magma ocean sustaining a denser atmosphere are shown to be dominated by $\mathrm{CO} \pm \mathrm{CO}_{2}$ and $\mathrm{H}_{2} \pm \mathrm{H}_{2} \mathrm{O}$ species, depending on $\mathrm{fO}_{2}$, sulfur species amounting to only $\sim 1 \%$. In contrast, volcanic gases supplied at later stages of Mars evolution, such as during the building of the Tharsis province, are shown to be significantly richer in sulfur, with $\mathrm{S}$ contents on average 10-100 times that of gases emitted by magmas on Earth. If degassing during such a period occurred in a tenuous atmosphere (1 bar or less), volcanic gases were dominated by $\mathrm{SO}_{2}$ rather than by $\mathrm{H}_{2} \mathrm{~S}$, which should have favored the acidification of any persistent water layer. The calculated amounts of S emitted by the Tharsis volcanic region turn out to be equivalent to a 20-60 m thick layer of sulfate minerals if uniformly covering the martian surface, in qualitative agreement with remote sensing of the martian regolith.
\end{abstract}

Keywords: Mars; sulfur; basalt; volcanic degassing; redox; mantle; atmosphere

\section{Introduction}

Both landed experiments and remote sensing instruments on spacecrafts sent to Mars have shown the martian regolith to be uniformly rich in sulfur, in the sulfate form ([Yen, 2005] and [Gendrin et al., 2005]), with abundances typically exceeding 2 orders of magnitude those of common sedimentary or igneous rocks on Earth ([Yen, 2005] and [Clark and Baird, 1979]). High sulfate contents can dramatically lower the $\mathrm{pH}$ of surface waters suppressing carbonate saturation in favor of sulfate minerals ([Fairen et al., 2004] and [Halevy et al., 2007]). Thorough chemical modeling of the low temperature mineral deposits due to leaching of surface waters suggests water-poor and $\mathrm{SO}_{4}{ }^{2-}$ rich solutions on Mars (King et al., 2004). This requires an oxidizing martian atmosphere (King et al., 2004) or that gaseous sulfur dioxide was conveyed directly to the atmosphere (Halevy et al., 2007). Although widely recognized, the abundance of sulfur on the martian surface remains hitherto poorly explained. Various hypotheses have been put forward to explain such an S-enrichment. For instance, sulfur-rich solutions could have derived from the weathering of S-bearing minerals, such as sulfides present in mafic-ultramafic rocks (King and McSween, 2005), and subsequently oxidized to 
sulfates. Such a process would require the presence of sulfur-rich volcanic rocks on the martian surface and a relatively oxidizing atmosphere (King et al., 2004). Clark and Baird (1979) indeed suggested that the remnants of primitive chondritic material during late accretion could have enriched the martian surface in sulfur. However, volcanic degassing is the most frequent hypothesis advocated to explain the S-enrichment of the martian regolith ([Bullock and Moore, 2007], [Halevy et al., 2007] and [Johnson et al., 2008]). Recent studies have examined the atmospheric impact of magmatic emissions on Mars using various thermodynamic approaches and assumptions ([Elkins-Tanton, 2008], [Hirschmann and Withers, 2008] and [Johnson et al., 2008]). Elkins-Tanton (2008) calculated the amounts of $\mathrm{H}_{2} \mathrm{O}$ and $\mathrm{CO}_{2}$ outgassed during the martian magma ocean stage, based on available solubility models for these components, and concluded that the atmospheric pressure during this epoch could have exceeded 100 bars, although such predictions do not take into account the very reducing conditions (i.e. low oxygen fugacity), which prevailed at this stage. Hirschmann and Withers (2008) calculated the $\mathrm{CO}_{2}$ vented by the post $4.5 \mathrm{Ga}$ volcanic activity of Mars. Based on the $\mathrm{CO}_{2}$ content of basalts saturated in graphite under the likely low oxygen fugacity conditions of the martian mantle, Hirschmann and Withers (2008) concluded that volcanic $\mathrm{CO}_{2}$ emissions were probably not high enough to account for greenhouse conditions required to support liquid surface waters, and suggested on this basis an evaluation of the extent and role of sulfur degassing. Wänke and Dreibus (1994), and more recently Halevy et al. (2007) and Johnson et al. (2008), have also proposed that volcanic sulfur could have played an important greenhouse role on early Mars. The model of Johnson et al. (2008), elaborated for the Tharsis province, indicates that a greenhouse warming of $25^{\circ} \mathrm{C}$ could be expected from the degassing of volcanic S-species (considered to be a mixture of $\mathrm{H}_{2} \mathrm{~S}$ and $\mathrm{SO}_{2}$ in equal concentrations), thereby showing that, on Mars at least, sulfur is a viable alternative to $\mathrm{CO}_{2}$ for a sustained greenhouse effect. Such a model, however, does not consider some of the martian basalt characteristics, such as their high iron content and relatively reduced redox state, and ignores the role of other gas species (i.e. $\mathrm{H}_{2} \mathrm{O}, \mathrm{H}_{2}, \mathrm{CO}_{2}, \mathrm{CO}, \mathrm{S}_{2}$ ), all parameters that can affect the sulfur yield of volcanic gases, as we show below.

Our work builds upon those previous efforts and examines in greater details the conditions that could have promoted high fluxes of volcanic sulfur into the martian atmosphere. Volcanic gases are emitted by magmas resulting from mantle melting. Therefore, our modeling requires first an estimation of the sulfur content in the mantle of Mars allowing the S-content in martian basalts to be evaluated. Then, based on multi-component gas-melt equilibria under redox, temperature, and pressure conditions relevant to Mars, we calculate the volcanic gas compositions that were vented through the different epochs of this planet and conclude that the delivery of volcanic gases with high $\mathrm{SO}_{2}$ content into the Martian atmosphere essentially occurred during the late volcanic events only (Tharsis).

\section{Foreword on sulfur abundance in terrestrial materials and its thermochemistry}

\subsection{Abundance}

Sulfur, the 10th most abundant element in the solar system ([Hilgren et al., 2000] and [Palme and Jones, 2003]), is probably the most complex heterovalent element. Its oxidation state in terrestrial materials ranges from - II to + VI, with many intermediate redox states ([Carroll and Webster, 1994] and [Behrens and Gaillard, 2006]). Sulfur content in chondrites is in the range 2 to $10 \mathrm{wt} . \%$, essentially as FeS (Table 1). Volatilization due to high temperature reached during early planetary accretion is thought to have decreased the amount of sulfur 
available in planetary bodies (Table 1; Dreibus and Palme, 1996). The earliest estimations of sulfur abundance on bulk Earth yielded values exceeding $5 \mathrm{wt} . \%$ (see review by Hilgren et al., 2000; see also Chabot, 2004). Recent geochemical constraints on Zn abundance on Earth, an element with a volatility similar to that of $\mathrm{S}$, suggest that the bulk S content of Earth is 0.56 wt.\% at best (Dreibus and Palme, 1996). A slightly lower content $(\sim 0.46 \mathrm{wt} . \%)$ has been more recently proposed (Allègre et al., 2001), also based on volatility trends.

The sulfur content of the silicate portion of terrestrial planets is relatively better constrained. The Earth mantle has been estimated to have $250 \mathrm{ppm} \mathrm{S}$ by McDonough and Sun (1995). This value represents the best average of various mantle lithologies such as the source region of MORBs and outcropping massif peridotites. For Mars, inferences have been drawn from the study of meteorites such as Shergottites, which are considered to derive from the martian magmatism (McSween, 1994). Shergottites have a high FeO content (18 wt.\%), which indicates that they derived from a planetary body that accreted under relatively oxidized conditions. They have relatively high sulfur contents, from 2000 to $3000 \mathrm{ppm}$ ([Gibson et al., 1985] and [Zipfel et al., 2000]), yet isotopic constraints reveal that most of the sulfur analyzed in these meteorites probably derived from atmospheric processes (Farquhar et al., 2000). The existence of planetary bodies with elevated S contents is indicated by Aubrite meteorites. Their very low $\mathrm{FeO}$ content indicates that they were extracted from an extremely reduced chondritic material sharing many features with enstatite chondrites. Aubrites contain the highest sulfur content of all achondrites ([Gibson et al., 1985] and [Fogel, 2005]) with bulk contents up to $10,000 \mathrm{ppm}$, some glass inclusions reaching up to $2.5 \mathrm{wt} \%$ dissolved S (Fogel, 2005). This brief overview shows that the sulfur content of the mantle of terrestrial bodies may thus vary significantly. In this work we show that such a variation does not necessarily require important changes in the bulk S content of those planets, but rather reflects differences in redox conditions prevailing during core formation that in turn significantly affected the abundance of sulfur of their mantle.

\subsection{Thermochemistry}

Sulfur is generally found in molten basalt in the $\mathrm{S}^{2-}$ form at redox conditions (i.e. oxygen fugacity: $\mathrm{fO}_{2}$ ) more reducing than one log unit above the $\mathrm{QFM}^{2}$ buffer (i.e. QFM + 1) (e.g. [Carroll and Webster, 1994], [O'Neill and Mavrogenes, 2002], [Scaillet et al., 2003], [Moretti and Ottonello, 2004] and [Behrens and Gaillard, 2006]), which corresponds to the conditions we are interested in for this paper. Under more oxidized conditions, sulfur is essentially in the $\mathrm{S}^{6+}$ form ([Carroll and Webster, 1994] and [Behrens and Gaillard, 2006]). The sulfur content of Earth basalts usually ranges from several hundreds to a few thousands ppm depending on the degree of fractionation of the magma ([Mathez, 1979], [Wallace and Carmichael, 1992] and [Saal et al., 2002]). Its partitioning between silicate melts and other S-bearing phases essentially depends on temperature, pressure and oxygen fugacity ([Holzheid and Grove, 2002], [O'Neill and Mavrogenes, 2002], [Scaillet et al., 2003], [Moretti and Ottonello, 2004], [Behrens and Gaillard, 2006] and [Scaillet and McDonald, 2006]). In this paper, we calculate the partitioning of sulfur between silicate melt and (1) metal iron, (2) molten sulfide, and (3) gas. Each partitioning relationships is supposed to mirror (1) magma ocean/metal iron equilibration, (2) mantle melting from a sulfide-saturated source, and (3) volcanic degassing. Our calculations provide thermodynamic constraints specific to the partitioning of sulfur between the core and mantle of both Mars and Earth, and illustrate how differences in the sulfur contents of these reservoirs may have affected the amount of sulfur delivered by volcanic degassing to the atmosphere of terrestrial planets. 
(1) Metal iron is uncommon in present-day basalts of any differentiated planets. However, it is thought to have been present in abundance before and during planetary differentiation, most likely in the molten form ([O'Neill, 1991] and [Li and Agee, 1996]). Sulfur is highly soluble in molten iron in the oxidation state 0 in the S-poor region of the $\mathrm{Fe}-\mathrm{S}$ binary. There is a continuous miscibility between S-free molten iron and molten FeS (Kress, 1997) that is however characterized by important deviations from ideal behavior (Wang et al., 1991, see Supplementary materials, SM in the Appendix). Sulfur partitioning between Fe-metal (oxidation state 0 ) and silicate melt (oxidation state - II) is later in this paper shown to be predominantly controlled by $\mathrm{fO}_{2}$. At present, it is difficult to evaluate the effect of pressure and temperature, owing to a lack of experimental data.

(2) Sulfides (FeS), either solid or liquid, are common phases found in terrestrial basalts ([Mathez, 1979], [Wallace and Carmichael, 1992] and [Kress, 1997]). The sulfur content in basalts saturated in sulfide has been extensively studied: it is influenced by temperature, pressure, sulfur fugacity, and nominally independent on oxygen fugacity (Mavrogenes and O'Neill, 1999). However, it is strongly controlled by chemical parameters, which are strongly

$\mathrm{fO}_{2}$ dependent ([O'Neill and Mavrogenes, 2002] and [Holzheid and Grove, 2002]). In particular, the ferrous iron content in basalts $(\mathrm{FeO})$ strongly depends on oxygen fugacity (Kress and Carmichael, 1991) and plays a critical role on the sulfur content in basalts saturated in sulfide ([Mathez, 1979] and [O'Neill and Mavrogenes, 2002]) as will be illustrated later.

(3) Sulfur in high temperature volcanic gases is mostly in the form $\mathrm{H}_{2} \mathrm{~S}, \mathrm{~S}_{2}$, and $\mathrm{SO}_{2}$ (e.g. Symonds et al., 1994). Temperature, pressure and $\mathrm{fO}_{2}$ control the relative abundance of these species in the gas (Symonds et al., 1994). Here we model the partitioning of sulfur between basaltic melt (oxidation state - II, a higher oxidation state would not be relevant for martian basalts given their $\mathrm{fO}_{2}$ range; Behrens and Gaillard, 2006) and gas (oxidation state - II, 0 , + IV) and we show that the pressure of volcanic gas delivery, the redox conditions, and the bulk water content, are the chief parameters controlling the amount and speciation of sulf ur outgassed.

\section{Sulfur content in the mantle of Mars and Earth}

It is being increasingly appreciated that, in response to repeated collisional events, the build up of terrestrial planets was accompanied by several large scale melting events leading to the so-called magma ocean ([Righter and Drake, 1996] and [Righter et al., 2007]), during which physical segregation of iron core and silicate material was, if not triggered, at least facilitated ([Li and Agee, 1996], [Rubie et al., 2004] and [Wood et al., 2006]). In such a scenario, the sulfur partitioning between molten metal and silicate can be written as:

$\underline{\mathrm{S}^{\text {metal }}+\mathrm{O}^{2-\text { silicate }}} \quad \underline{\mathrm{S}^{2-\text { silicate }}+1 / 2} \mathrm{O}_{2}$

in which oxygen anions in the silicate melt, $\mathrm{O}^{2-}$, are substituted by sulfur anions, $\mathrm{S}^{2-}$, depending on the prevailing oxygen fugacity $\left(f \mathrm{O}_{2}\right)$, which is defined by the equilibrium: 
$\underline{\mathrm{Fe}^{\text {metal }}+1 / 2 \mathrm{O}_{2}} \quad \underline{\mathrm{FeO}^{\text {liq }}}$

The law mass action of Eq. (1) can be formulated as follows (see supplementary materials in the Appendix):

$\ln \frac{X_{S 2-}^{\text {silicate }}}{X_{S}^{\text {metal }}}=-\ln K_{S M-3}+\ln \gamma_{S}^{\text {metal }}+\ln C_{S}^{\text {silicate }}-\frac{1}{2} \ln f_{02}$

where $K_{\mathrm{SM}-3}$ is the thermodynamic constant of the reaction of gaseous sulfur solubilization in the metal (see Wang et al., 1991 and Supporting Material, SM in the Appendix), $\gamma_{S}{ }^{\text {metal }}$ the activity coefficient of sulfur in the molten Fe-S system (Wang et al., 1991), and $C_{S}{ }^{\text {silicate }}$ the sulfur capacity defined as (e.g., O'Neill and Mavrogenes, 2002):

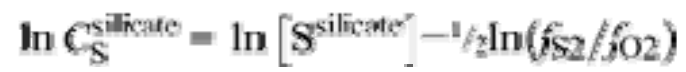

where $S^{\text {silicate }}$ is the sulfur content in the silicate melt (ppm weight) and $f S_{2}$ the sulfur fugacity. Under the low $f \mathrm{O}_{2}$ conditions relevant to early planetary processes, $C_{\mathrm{S}}$ silicate essentially depends on the FeO content of the molten silicate (O'Neill and Mavrogenes, 2002).

Equilibrium (2) states that $f \mathrm{O}_{2}$ is fixed by the $\mathrm{FeO}$ content of the molten silicate. In this work we use the following relationships (see Gaillard et al., 2003 F. Gaillard, M. Pichavant and B. Scaillet, Experimental determination of activities of $\mathrm{FeO}$ and $\mathrm{Fe}_{2} \mathrm{O}_{3}$ components in hydrous silicic melts under oxidizing conditions, Geochimica et Cosmochimica Acta 67 (2003), pp. 4389-4409.

$$
\begin{aligned}
\log f_{\mathrm{O}_{2}}= & \frac{-24916}{T}+0.913+0.06 \times \frac{P}{T}+2.122 \times \log \left(\text { FeO wt.\% } \%^{\text {silicare }}\right) \\
& -2 \times \log \left(a_{\mathrm{Fe}}^{\text {metal }}\right)
\end{aligned}
$$

Combining the above equilibria and mass balance constraints, we have calculated the partitioning of sulfur between molten silicate and metal at $1600{ }^{\circ} \mathrm{C}$ and $1 \mathrm{~atm}$, for a bulk composition matching volatile (C, H) free CI-chondrites ([McDonough and Sun, 1995] and [Palme and Jones, 2003]), and for iron redox states ranging from all $\mathrm{Fe}$ to virtually all $\mathrm{FeO}$, depending on $f \mathrm{O}_{2}$.

Bulk sulfur content is adjusted in order to match the inferred sulfur content of the Earth mantle (ca. $250 \mathrm{ppm}$ ) but additional calculations performed with higher bulk $\mathrm{S}$ contents are shown in the supplementary data in the Appendix. We performed all calculations at 1 atmosphere pressure since the data needed to compute $\mathrm{S}$ partitioning between metal and silicate melts at elevated pressures are scarce, yet those available suggest that increasing pressure should amplify the trends shown below ([Li and Agee, 1996], [Kilburn and Wood, 1997], [Mavrogenes and O'Neill, 1999] and [Holzheid and Grove, 2002]; see below and supplementary materials in the Appendix). It must be stressed that, apart from the Kilburn and Wood (1997) study, all the above mentioned papers deal with the effect of pressure on sulfur 
content at FeS saturation (i.e. a system very rich in sulfur), which almost certainly differs from the metal Fe-silicate partitioning addressed here. The composition of the molten metal phase was simplified to $80 \mathrm{wt} . \%$ Fe plus $20 \mathrm{wt} . \%$ of additional elements (Ni, Co, light elements; [Righter and Drake, 1996] and [Righter et al., 2007]). Any changes in $\mathrm{fO}_{2}$ should change the $\mathrm{Ni}$ and Co content, but we consider that these mix ideally with $\mathrm{Fe}$ (implying that their content in Fe-metal does not have any effect on the $\mathrm{S}$ content). We assume that $f \mathrm{O}_{2}$ is imposed by the $\mathrm{FeO}$ content of the mantle, which for Earth and Mars is inferred to be 8 and 18 wt.\%, respectively ([Rubie et al., 2004], [Righter and Drake, 1996] and [Righter et al., 2007]). Whether such a bulk redox state is an early (i.e. acquired early during accretion before Solar nebula dissipation), or/and a relatively late characteristic (such as due to temperature control on oxygen solubility in molten iron which depends on planet size, Rubie et al. (2004)), is still debated (Wood et al., 2006).

We consider the case of a bulk sulfur content of $0.35 \mathrm{wt} . \%$, similar to the range of values suggested for Earth on the basis of volatility trends during accretion ([Dreibus and Palme, 1996] and [Allègre et al., 2001]). This yields a sulfur abundance of the Earth mantle ( $\left.S^{\text {silicate }}\right)$ of $250 \mathrm{ppm}$, as inferred from geochemical arguments ([McDonough and Sun, 1995] and Saal et al., 2002 A.E. Saal, E.H. Hauri, C.H. Langmuir and M.R. Perfit, Vapour undersaturation in primitive mid-ocean-ridge basalt and the volatile content of Earth's upper mantle, Nature 419 (2002), pp. 451-455.. For such a bulk sulfur content, $1.2 \mathrm{wt} . \%$ of $\mathrm{S}$ is dissolved in the metal (Fig. 1) (i.e. the core), in agreement with high pressure experiments (Kilburn and Wood, 1997), and density calculations based on equation of state of compounds in the Fe-FeS system at high pressure (Sherman, 1997), which both suggest that the sulfur content of Earth's core is unlikely to be higher than $2 \mathrm{wt} . \%$. Such an agreement would suggest that the S content of Earth mantle preserves the equilibrium value expected from a widescale magma ocean stage (note that increasing the temperature would slightly decrease $\mathrm{S}^{\text {bulk }}$ : at $1750{ }^{\circ} \mathrm{C}$, for an Earth mantle also set at $250 \mathrm{ppm} \mathrm{S}$, the core would contain $0.75 \mathrm{wt} . \% \mathrm{~S}$ and the bulk terrestrial S content would be slightly less than $0.3 \mathrm{wt} . \%)$.

Using the same bulk sulfur content for Mars yields $\mathrm{S}^{\text {silicate }}=900 \mathrm{ppm}$ (Fig. 1). Unfortunately, this estimate can hardly be compared with Shergotty meteorites because their actual Scontents partly reflect atmospheric exposure and related surficial processes (Farquhar et al., 2000). The equilibrium $\mathrm{S}$ content in the metal is $1.5 \mathrm{wt} . \%$ (Fig. 1), which is significantly lower than the generally quoted value of 10-12 wt.\% ([McSween, 1994] and [Stewart et al., 2007]). Calculations (Fig. S.M.4) show that $10 \mathrm{wt} . \%$ sulfur in the Mars's core requires $\mathrm{S}^{\text {bulk }}=3 \mathrm{wt} . \%$, corresponding to $\mathrm{S}^{\text {silicate }}=8600 \mathrm{ppm}$ (for Earth such an $\mathrm{S}^{\text {bulk }}$ would imply that $\mathrm{S}^{\text {metal }}=9 \mathrm{wt} . \%$ and $\mathrm{S}^{\text {silicate }}=2800 \mathrm{ppm}$, which are well above geochemically derived values). Therefore, for most of the calculations shown after (Sections 2.2 and 3), we considered a martian mantle containing 600-900 ppm S but additional S-richer cases are shown in the Supplentary materials in the Appendix in keeping with the above statements.

As noticed previously, higher pressure of metal-magma ocean equilibration on Earth than on Mars could modify the above figures of sulfur content. Our model is not calibrated against high pressure data, but it reproduces well the data of Kilburn and Wood (1997) that were obtained at $\sim 1-2 \mathrm{GPa}$, thus suggesting a small pressure effect. However, high pressure experiments on the $\mathrm{S}$ content of silicate melts saturated in $\mathrm{FeS}$ indicate that sulfur becomes more "siderophile" as pressure increases ( $\mathrm{Li}$ and Agee, 1996). This pressure effect could also persist for equilibration between silicate melt and S-poor molten Fe metal but experimental constraints are currently lacking and the strong deviation from ideality in the $\mathrm{Fe}-\mathrm{FeS}$ system (Wang et al., 1991) seriously hinders the direct extrapolation of the effect of pressure on 
molten silicate in equilibrium with $\mathrm{FeS}$ to the effect of pressure on molten silicate in equilibrium with S-poor molten iron. Nevertheless, considering such a hypothetical pressure effect would reinforce our conclusion in that higher pressures of metal-silicate equilibration on Earth would make sulfur more siderophile and would therefore support that the Earth mantle would be less S-rich than its martian counterpart.

\section{Sulfur content of martian basalts}

Our calculations therefore point toward sulfur contents of Earth and Mars mantles of 250 and 600-900 ppm, respectively, if the bulk sulfur content during the magma ocean stage was about 0.35 wt.\%. In this scenario, assuming 10\% partial melting of the Earth mantle (e.g., Niu, 1997) and sulfur behaving incompatibly would yield basalt melts with ca $2500 \mathrm{ppm}$. This amount largely exceeds the average S-content of undegassed MORBs, which is around 800 ppm (Saal et al., 2002). However, asides from FeO content and temperature, the sulfur content of a basalt saturated in $\mathrm{FeS}$ is also controlled by pressure, such that the sulfur content of a basalt melt at sulfide saturation decreases with increasing pressure (Fig. 2, [Mavrogenes and O'Neill, 1999] and [Holzheid and Grove, 2002]). Thus, owing to this pressure dependency, an upper likely limit of the sulfur content of basalts is given by the conditions under which sulfide (FeS) saturation is reached in the source prior to extraction. For Earth this would result in a melt sulfur content before extraction of 800 ppm (Fig. 2), in agreement with undegassed MORBs (Saal et al., 2002). Considering now the case of Mars, 10\% of mantle melting would yield basaltic liquids with $c a 6000-9000$ ppm dissolved sulfur. Experimental work indicates that strongly depleted martian basalts were last equilibrated at around $1.2 \mathrm{GPa}$, $1540{ }^{\circ} \mathrm{C}$ (Musselwhite et al., 2006), which are conditions allowing the basalt melt saturated in sulfide to dissolve more than 1 wt.\% sulfur (Fig. 2). This would imply a near complete extraction of sulfur during melting of the martian mantle. More recent work suggests, however, a lower temperature $\left(1320^{\circ} \mathrm{C}\right)$ for less depleted martian basalts but a similar pressure of last equilibration (Monders et al., 2007), which would imply an S content in the basalt melt slightly higher than $4000 \mathrm{ppm}$. In addition to the role of pressure, Fig. 2 illustrates the critical effect of iron content of the basalt on its dissolved sulfur content when sulfide saturated. Because martian basalts contain twice as much $\mathrm{FeO}$ as those on Earth, they can dissolve up to 3 to 4 times more sulfur under similar conditions of pressure and temperature. A martian basalt with slightly less than $4000 \mathrm{ppm} \mathrm{S}$, as calculated above, would be saturated in molten sulfide at $P \sim 2 \mathrm{GPa}$ for temperature of $1300{ }^{\circ} \mathrm{C}$. For comparison, as shown before, Earth basalts can dissolve no more than 800 ppm sulfur under such $P-T$ conditions (Fig. 2). Whatever the initial sulfur content, the negative pressure dependence of basalts with respect to sulfide saturation ([Mavrogenes and O'Neill, 1999] and [Holzheid and Grove, 2002]) precludes sulfide fractionation during magma ascent. Therefore, most of the sulfur dissolved in the magma at the source is very likely conveyed to the surface and possibly released into the atmosphere during the eruption as will be shown below.

The initial sulfur content of martian basalts is thus shown here to be at least of $4000 \mathrm{ppm} \mathrm{S}$, which is significantly higher than the $1400-1700 \mathrm{ppm} \mathrm{S}$ of Johnson et al. (2008). The reason is that Johnson et al. (2008) used the Holzheid and Grove (2002) empirical formulation, which is calibrated on FeO-poor compositions (relative to Mars), whereas we used here the complete sulfur capacity model of O'Neill and Mavrogenes (2002) in order to account for the effect of elevated $\mathrm{FeO}$ content in martian basalts on the sulfur content at FeS saturation. We note that the extremely high temperature retrieved by Musselwhite et al. (2006) imposes very high sulfur contents in the basalt ( $>1$ wt.\%, Fig. 2). According to Hirschmann and Withers (2008), such a high temperature is difficult to reconcile with the thermal evolution of the 
martian lithosphere, and comes from the fact that the Shergottite Y980459 used by Musselwhite et al. (2006) might not be representative of martian basalts. We therefore conclude that the S content of martian basalt is more likely in the range 4000-7000 ppm, which would correspond to equilibration temperatures with an FeS saturated mantle at $1 \mathrm{GPa}$ and at $1300-1400^{\circ} \mathrm{C}$.

\section{Degassing of sulfur}

\subsection{Modeling magmatic degassing of COHS species from a basalt}

Using the above results, the sulfur contents of volcanic gases in equilibrium with martian basalts can be calculated using thermodynamic (Holloway, 1987) and mass balance constraints ([Scaillet and Pichavant, 2004] and [Burgisser and Scaillet, 2007], see Supplementary materials in the Appendix), assuming that the gas phase can be described in the COHS system, as for terrestrial magmas (Symonds et al., 1994) and using the model of Kress and Carmichael (1991) to relate $\mathrm{fO}_{2}$ to the $\mathrm{Fe}^{3+}-\mathrm{Fe}^{2+}$ ratio of the melt. In our analysis, we incorporate potential changes in $\mathrm{fO}_{2}$ that have been shown to affect rhyolitic magma (Burgisser and Scaillet, 2007) and basalts (Mathez, 1984) during degassing. Calculations are performed over a temperature range $1300-1600{ }^{\circ} \mathrm{C}$, which encompasses emission temperatures of most martian basalts ([Monders et al., 2007], [Musselwhite et al., 2006], [Hirschmann and Withers, 2008] and [Johnson et al., 2008]) and of the martian magma ocean stage (Elkins-Tanton, 2008). Pressure was varied between 1000 and $10^{-2}$ bar, simulating degassing from a dense atmosphere down to the present-day atmospheric pressure on Mars.

Two sets of simulations are shown below. The first set (Section 5.2) shows the degassing within a dense atmosphere, and under reduced conditions, of a melt composition akin to that of a magma ocean, including its $\mathrm{C}-\mathrm{O}-\mathrm{H}$ volatile content ([Elkins-Tanton, 2008] and [Hirschmann and Withers, 2008]), and with a sulfur content based on the above estimate for the martian mantle (900 ppm, Fig. 1). The second set of simulations (Section 5.3) addresses the degassing of basalts resulting from the post $4.5 \mathrm{Ga}$ activity of Mars. Such basalts were possibly more oxidized and most likely degassed into an atmosphere having a low density, perhaps comparable to the present-day martian atmosphere.

\subsection{Magmatic degassing of COHS species from the martian magma ocean}

Elkins-Tanton (2008) has shown that magma ocean degassing might have injected enormous amounts of $\mathrm{H}_{2} \mathrm{O}$ and $\mathrm{CO}_{2}$ into the early atmosphere resulting in atmospheric pressures $>100$ bars with important implications for the early greenhouse warming on Mars. We compute here in addition to $\mathrm{H}_{2} \mathrm{O}$ and $\mathrm{CO}_{2}$ the potential degassing of sulfur species. Furthermore, because our analysis considers redox equilibria, we calculate the relative abundances of reduced species such as $\mathrm{H}_{2}$ and $\mathrm{CO}$ in the gas phase. The $\mathrm{fO}_{2}$ range over which calculations were performed rests on the following evidence. Firstly, Eq. (5), together with the $\mathrm{FeO}$ content of the martian mantle, indicate that core formation from the martian magma ocean took place at $\sim \mathrm{IW}-1.5$. Once segregation of the Fe-metal occurred, the $\mathrm{fO}_{2}$ could have changed due to crystallization and degassing of the magma ocean. Secondly, the post $4.5 \mathrm{Ga}$ oxidation state of the martian mantle might have been at the low end of the oxygen fugacity recorded by the SNC meteorites, a possibility which lead Hirschmann and Withers (2008) to define an early martian mantle oxygen fugacity between IW and IW +1 . The degassing paths shown in Fig. 3 are therefore calculated in the $\mathrm{fO}_{2}$ range $\mathrm{IW}-1.5 / \mathrm{IW}+1$. The martian mantle sulfur content is taken at $900 \mathrm{ppm}$ (see part 3). We use an initial melt water content at 
0.1 wt.\% (Elkins-Tanton, 2008) and $\mathrm{CO}_{2}$ in the range 10-700 ppm depending on $\mathrm{fO}_{2}$ (Hirschmann and Withers, 2008). The temperature is fixed at $1600{ }^{\circ} \mathrm{C}$ but changes of $+/-100{ }^{\circ} \mathrm{C}$ do not significantly affect the results. The results of such calculations illustrate the critical importance of $\mathrm{fO}_{2}$. In the most reduced case, i.e. at Fe metal saturation, the gas is dominated by $\mathrm{CO}$ and $\mathrm{H}_{2}$, with $\mathrm{H}_{2} \mathrm{O}$ becoming significant (at the level of $10 \%$ ) at pressures $<10$ bars only. In the most oxidized case (IW+1), $\mathrm{CO}$ and $\mathrm{CO}_{2}$ dominate the gas in equal proportions and, as under reduced conditions, water reaches significant concentrations only at low pressures. In all cases, the degassing of sulfur species remains very small because at $\mathrm{fO}_{2}<\mathrm{IW}+1$, sulfur is much more stable in the melt than in the gas (O'Neill and Mavrogenes, 2002). In the most favorable case (i.e. IW+ 1), it is only for pressures lower than 10 bars that the concentration of sulfur species in the gas exceeds $1 \%$. Therefore, assuming that degassing during magma ocean stage produced high atmospheric pressures $(>\sim 100$ bars of gas, ElkinsTanton, 2008), then it follows that volcanic gases would have been almost S-free and dominated by $\mathrm{CO}, \mathrm{H}_{2}$ and to a lesser extent, water. As frequently pointed out, in the low gravity setting of Mars, most $\mathrm{H}_{2}$ would be rapidly dissipated in space, thereby oxidizing the atmosphere and driving it toward $\mathrm{CO}_{2}$-rich conditions (King et al., 2004 P.L. King, D.T. Lescinsky and H.W. Nesbitt, The composition and evolution of primordial solutions on Mars, with application to other planetary bodies, Geochimica et Cosmochimica Acta 68 (2004), pp. 4993-5008. [King et al., 2004] and [Halevy et al., 2007]). In Fig. 4 in Supplementary materials in the Appendix, we also show the degassing path for a magma richer in volatiles than above, in an effort to explore the degassing of the very last portion of liquid accompanying the solidification of the magma ocean. It turns out that the above scenario remains unchanged: both $\mathrm{CO}$ and $\mathrm{H}_{2}$ dominate, water and $\mathrm{CO}_{2}$ remain at low concentration levels, and sulfur species reach the $1 \%$ level at best.

\subsection{Post 4.5 Ga magmatic degassing of COHS species}

It is probable that the martian crust was formed during the early pre- 4.5 Ga by processes following the magma ocean solidification (Elkins-Tanton et al., 2005). The magmatic production associated to this event remains, however, uncertain with respect to either style vigor, or composition ([Elkins-Tanton et al., 2005] and [Hirschmann and Withers, 2008]), which prevents from a quantitative assessment of the volcanic sulfur yield during that period.

In contrast, the conditions of the post $4.5 \mathrm{Ga}$ magmatism that formed the Tharsis province can be better constrained, in particular in light of the experimental work performed by Monders et al. (2007) ([Hirschmann and Withers, 2008] and [Johnson et al., 2008]) and of the chemical analyzes of Shergottites ([Herd et al., 2002], [Herd, 2003], [Righter et al., 2007] and [Wadhwa, 2001]). These constraints indicate $T \sim 1300{ }^{\circ} \mathrm{C}$ and $\mathrm{fO}_{2}$ in the range QFM-3 to QFM-1, (i.e. $\sim$ IW +0.5 to IW +3 ). Although most results exposed here simulate the degassing of basalts with $0.2 \mathrm{wt} . \%$ water, we explored a range of water contents from 0.05 up to 0.8 wt. $\% \mathrm{H}_{2} \mathrm{O}$, since there is currently no consensus as to either the water-poor or water-rich character of martian basalts ([McSween et al., 2001], [Herd et al., 2005] and [Elkins-Tanton, 2008]). In the Supplementary materials in the Appendix file, we show the effect of temperature together with changes in $\mathrm{fO}_{2}$ and water content (Figs. 4-6 in Supplementary materials in the Appendix). According to the $\mathrm{fO}_{2}$ dependence model of Hirschmann and Withers, 2008 M.M. Hirschmann and A.C. Withers, Ventilation of $\mathrm{CO}_{2}$ from a reduced mantle and consequences for the early martian greenhouse, Earth and Planetary Science Letters 270 (2008), pp. 147-155, the $\mathrm{CO}_{2}$ content of such basalts lies in the range 80$900 \mathrm{ppm}$, which is similar to that inferred for terrestrial basalts ([Saal et al., 2002], [Cartigny et al., 2008] and [Gaillard et al., 2008]). In keeping with the estimates above, we mainly used 
an initial melt sulfur content of $4000 \mathrm{ppm}$, though a few additional calculations for an $\mathrm{S}$ content of 7000 ppm were performed.

In the following description, we first focus on the extent of sulfur degassing out of the melt and then describe its abundance and speciation in the gas. In all cases the master variables appear to be the pressure of degassing, the pre-eruptive $\mathrm{fO}_{2}$ and the initial melt water content. Fig. 4a shows the sulfur content in the melt during degassing upon decompression over a pressure range 1000 to 0.01 bar. The overall decrease in $S$ content in the melt as pressure decreases obviously reflects the fact that sulfur is partitioned toward the gas phase; however, extensive sulfur degassing only initiates at pressures $<50$ bars. In general, the more oxidized and/or the more water-rich, the more sulfur is extracted from the melt. For $0.2 \mathrm{wt} . \%$ water, at QFM-3.5 (i.e., IW+ 0.5 the most reducing magmatic $\mathrm{fO}_{2}$ so far recognized on Mars), the $\mathrm{S}$ content in the basalt decreases from 4000 to $2500 \mathrm{ppm}$ at 0.01 bar, whereas at QFM-1 (the most oxidizing conditions recognized for martian basalts), the $\mathrm{S}$ content in the melt decreases to less than $1500 \mathrm{ppm}$ at 0.01 bar. In the case of a dry reduced basalt ( $0.05 \mathrm{wt} . \%$ water $)$, sulfur does almost not exsolve and the basalt melt still contains $3500 \mathrm{ppm} \mathrm{S}$ at 0.01 bar. For the same reduced basalt but containing $0.8 \mathrm{wt} . \%$ water, the $\mathrm{S}$ content in the melt at $0.01 \mathrm{bar}$ would be less than $800 \mathrm{ppm}$. For the same water content and the same pressure but considering the oxidized end-member (QFM-1), the S content in the melt at 0.01 bar is even lower, falling below $500 \mathrm{ppm}$. In summary, an oxidized and water-rich martian basalt could have delivered up to $3500 \mathrm{ppm} \mathrm{S}$ into the atmosphere (and more if more hydrous than 0.8 wt.\%). Conversely, a reduced and water-poor martian basalt would degas less than $500 \mathrm{ppm}$, the bulk of the sulfur remaining dissolved in the basalt, probably ending up as sulfides during crystallisation.

The evolution of the composition of the gas phase during decompression requires a thorough description because of its complex multi-component nature. A typical degassing path of a martian basalt is shown in Fig. $5\left(1300{ }^{\circ} \mathrm{C}\right.$, QFM-2, 0.2 wt.\% water, 700 ppm $\mathrm{CO}_{2}, 4000$ $7000 \mathrm{ppm} \mathrm{S}$ ). The changes in relative abundances of gas species primarily reflect their contrasted solubilities in the silicate melt (Behrens and Gaillard, 2006) and the interplay with homogeneous equilibria in the gas phase in response to pressure changes ([Holloway, 1987] and [Symonds et al., 1994]). The gas venting at pressures $>20$ bars is dominated by $\mathrm{CO}_{2}$ and $\mathrm{CO}$. At lower pressures, water is the most abundant gas component. Sulfur species reach the $1 \%$ level at pressures lower than a few tens of bars. Interestingly, the S-species stable in the range a few tens of bars to a few bars is $\mathrm{H}_{2} \mathrm{~S}$. At lower pressures, $\mathrm{S}_{2}$ and $\mathrm{SO}_{2}$ become dominant. At a pressure of $0.1 \mathrm{bar}$, the $\mathrm{SO}_{2}$ concentration is the highest and reaches $\sim 10 \mathrm{~mol} \%$ of the gas. In addition, at such a pressure and for basalts initially having $4000 \mathrm{ppm}$ $\mathrm{S}, \mathrm{S}_{2}$ constitutes up to $20 \mathrm{~mol} \%$ of the gas, which brings the total fraction of sulfur bearing species to $30 \mathrm{~mol} \%$. For the S-rich case (7000 ppm), at $0.1 \mathrm{bar}$, the total fraction of S-species is $\sim 40 \mathrm{~mol} \%$. Such a high sulfur fraction in the gas is due to the enhanced extraction of sulfur from the melt at low pressure and to the high sulfur content in the basalt (note however that at 0.01 bar for such a water content and $\mathrm{fO}_{2}$, the basalt has still 2000-3500 ppm dissolved sulfur for initial S-contents of 4000-7000 ppm, respectively). The increasing fractions of $\mathrm{SO}_{2}$ and $\mathrm{S}_{2}$ over $\mathrm{H}_{2} \mathrm{~S}$ as pressure decreases are due to the well known pressure effect on the redox reactions governing the abundances of those two species:

\section{$\underline{2 \mathrm{H}_{2}} \underline{\mathrm{S}} \quad \underline{\mathrm{S}}_{2}+2 \mathrm{H}_{2}$}




\section{$\underline{2 \mathrm{H}_{2} \mathrm{O}+\mathrm{H}_{2}} \underline{\mathrm{S}} \quad \underline{\mathrm{SO}_{2}} \underline{+3 \mathrm{H}_{2}}$}

Both reactions (6) and (7) are driven rightward as pressure decreases due to the imbalance in the total number of moles involved on both sides of the equilibria (Symonds et al., 1994). For all degassing calculations we have performed, at pressures lower than a few bars, and in the $\mathrm{fO}_{2}$ range of martian basalts (down to IW), $\mathrm{SO}_{2}$ dominates over $\mathrm{H}_{2} \mathrm{~S}$ (see Fig. 5 and Figs. 5-7 in Supplementary materials in the Appendix).

The total sulfur content of the gas and its speciation not only depend on pressure but they also vary with the bulk volatile contents and the redox conditions (Fig. $4 \mathrm{~b}$ and c). For a given water content, the sulfur content in the gas increases with increasing $\mathrm{fO}_{2}$, which is a direct consequence of the $\mathrm{fO}_{2}$ effect on the amount of sulfur degassed as shown in Fig. 4a. At 0.01 bar, for the most oxidized conditions (QFM-1), the total sulfur content in the gas reaches $35 \mathrm{~mol} \%$, against $25 \%$ at IW. High water content has a dramatic effect on the gas sulfur content essentially because of dilution effects. Indeed, a basalt initially containing $0.8 \mathrm{wt} . \%$ dissolved water would end up having a gas phase dominated by water and, whatever the initial $\mathrm{fO}_{2}$, the bulk S content of the gas phase remains below $20 \mathrm{~mol} \%$ (which would still correspond to sulfur-rich volcanic gases on Earth). At first sight, this appears conflicting with Fig. 4 which clearly shows that the extraction of sulfur from the melt is favored by the presence of water, but the diluting effect of $\mathrm{H}_{2} \mathrm{O}$ due to high bulk water content dominates here. In contrast, dry basalts, such as shown in Fig. 4, retain their sulfur in the melt but yield the sulfur richest gas. Indeed, the calculation at QFM-1 (oxidized) shows that the dry basalt has a gas phase with up to $50 \mathrm{~mol} \%$ of S-species (Fig. 4b). This is a consequence of the very low water content in the system, which implies a low water content in the gas.

The fraction of sulfur in the $\mathrm{SO}_{2}$ form is $>40 \%$ for the most oxidizing conditions whatever the water content is (Fig. 4c). In contrast, for the lowermost $\mathrm{fO}_{2}$ conditions explored, the $\mathrm{SO}_{2}$ fraction is relatively small and remains below $20 \%$. However, in the case of water-rich and reduced conditions, the $\mathrm{SO}_{2}$ fraction strongly increases with decreasing pressure owing to reaction (7). At a degassing pressure of 0.1 bar, the $\mathrm{SO}_{2}$ fraction of such a reduced and hydrous basalt is $40 \mathrm{~mol} \%$. In all cases (regardless of water content and $\mathrm{fO}_{2}$ ), for pressures lower than a few bars, the fraction of sulfur in the $\mathrm{H}_{2} \mathrm{~S}$ form becomes negligible and $\mathrm{SO}_{2}$ or $\mathrm{S}_{2}$ dominate the gas (see Figs. 5-6 in Supplementary materials in the Appendix). The relative abundance of $\mathrm{SO}_{2}$ and $\mathrm{S}_{2}$ is then essentially controlled by $\mathrm{fO}_{2}$ and water content, which both favor $\mathrm{SO}_{2}$.

\subsection{Conditions of volcanic gas delivery on Mars}

We have shown that the nature of the volcanic gases and their sulfur content heavily depend on the pressure of emissions, which can be approximated by the atmospheric pressure. Nowadays, the atmospheric pressure is very low, around 0.007 bar, but such a condition probably did not prevail during all the geological history of Mars. Several works have shown that the martian atmospheric pressure may have been much higher in the past, depending in part on the extent of volcanic degassing. For example, Elkins-Tanton (2008) showed that the early Mars could have had an atmospheric pressure on the order of 100 bars due to degassing accompanying the magma ocean cooling at around $4.5 \mathrm{Ga}$. This however heavily depends on assumptions of the initial volatile inventory of early Mars on which there is no clear consensus ([Pepin, 2006] and [Ikoma and Genda, 2006]). How, as well as when, the martian 
atmosphere shifted from its putative early dense status toward its present-day teneous character remains difficult to constrain. It is possible that most of the early atmosphere was lost when the dynamo (active core), which was shielding the planet from solar sputtering losses, switched off (Pepin, 2006 and references therein). In addition, our calculations show that an important part of volatile species released by magmas would be composed of $\mathrm{H}_{2}$ (in addition to $\mathrm{CO}$ ), which would probably not remain in the atmosphere but would be rather lost in space. A continuous volcanic input would counteract gravitational escape and any sort of atmospheric erosion processes ([Pepin, 2006] and [Barabash et al., 2007]) that would tend to dissipate the atmosphere. It remains, however, that both factors (end of dynamo and gravitational loss) make estimations of the pressure of the earliest martian atmosphere still largely conjectural. For the post 4.5 Ga period, however, Hirschmann and Withers (2008) concluded that the $\mathrm{CO}_{2}$ delivered into the martian atmosphere was probably low (maximum of 1.4 bar). Thus, apart from the very early stages, it seems that the pressure of delivery of volcanic gases on Mars was possibly low in comparison to that on Earth, inasmuch the high altitude of martian volcanic vents is considered (Mt. Olympus culminates at $27 \mathrm{~km}$, therefore a large volume of magma was emitted at altitudes $>10 \mathrm{~km}$ ). Even if degassing were to occur beneath a substantial ocean layer as proposed for Mars (Knoll and Grotzinger, 2006), pressure would not exceed a few bars (i.e. 2 bars for a $50 \mathrm{~m}$ thick ocean). In summary, the early martian atmosphere could have been high (few bars to tens of bars) whereas it seems likely that the post $4.5 \mathrm{Ga}$ of martian history was dominated by low atmospheric pressure conditions.

\subsection{Magmatic degassing on Mars versus Earth}

The low atmospheric pressure reigning during magmatic degassing on Mars after the $4.5 \mathrm{Ga}$ period and the high S content in the magma both imply a high $\mathrm{S}$ content in the gas phase. Fig. 4 and Fig. 5 (see also Figs. 4-6 in Supplementary materials in the Appendix) indeed show that up to $50 \mathrm{~mol} \%$ of the post $4.5 \mathrm{Ga}$ martian volcanic gases could have been composed of Sspecies, with $\mathrm{SO}_{2}$ being the most abundant species for many investigated conditions (Fig. 4, Figs. 5-6 in Supplementary materials in the Appendix). Such a high S-content strongly contrasts with volcanic gases on Earth (either MORBs degassing below the oceans or during early magmatic degassing in a denser atmosphere). Our calculations show that the S contents of volcanic exhalations from magmatism at mid ocean ridges, i.e. at a few hundreds bars, should be typically $0.1-1 \%$ (Figs. $4-6$ in Supplementary materials in the Appendix). MORBs constituting $75 \%$ of present-day extrusive magmatism (e.g. Scaillet et al., 2003), they can be considered as representative of the global Earth degassing. Arc volcanism is dominated by andesites that are essentially venting water with low sulfur content $(<1 \%)$ (Symonds et al., 1994). A few subaerial volcanoes (Mt. Etna, Kilauea) produce sulfur-rich gases, with $\mathrm{S}$ content up to 10-20 mol\% $\mathrm{SO}_{2}$ (Symonds et al., 1994) but they represent a small fraction of the global volcanism on Earth ( $\sim 10 \%$ of extrusive rocks on Earth, e.g. Scaillet et al., 2003). We thus conclude that volcanic gases emitted during the post $4.5 \mathrm{Ga}$ period on Mars were on average 10-100 times richer in S than the average volcanic gases released on Earth.

\section{Surface waters and atmosphere on ancient Mars}

The late Noachian period, which followed the chaotic early Mars ([Hirschmann and Withers, 2008] and [Elkins-Tanton, 2008]), and during which the voluminous Tharsis province was active (Phillips et al., 2001), was possibly a period of high sulfur volcanic emissions into the tenuous martian atmosphere. The amount of basalts emitted from these volcanic centers has been estimated at $3 \times 10^{8} \mathrm{~km}^{3}$ (Phillips et al., 2001). Our calculations show however that S- 
rich gases can be prevented if Tharsis basalts were dry $\left(0.05\right.$ wt. $\left.\% \mathrm{H}_{2} \mathrm{O}\right)$ and reduced $(\sim \mathrm{IW})$. If such magmas, whose redox condition and $\mathrm{H}_{2} \mathrm{O}$ content are within the range expected for Mars basalts ([Herd et al., 2002], [Herd, 2003], [Righter et al., 2007] and [Wadhwa, 2001]), constituted the dominant part of the Tharsis province, then we do not expect any exceptionally high sulfur delivery into the atmosphere. In such a case, sulfur would remain in the basalt during eruption, either as sulfides if cooling was slow enough following lava extrusion or dissolved in the matrix glass. In such a scenario, the particularly S-rich character of the martian regolith could have thus come from the weathering of either sulfides or volcanic glass present in exposed mafic-ultramafic rocks (King and McSween, 2005). Since the sulfur content of martian basalts is in the range $4000-7000 \mathrm{ppm}$, exceeding by a factor of 4 to 7 the one of basalts on Earth, the observed S-enrichment on the martian regolith could thus be due to the basaltic component being itself richer in $S$ than Earth basalts. The details of the mechanism(s) through which sulfur was leached from the basalt and concentrated in the regolith as sulfate minerals remain, however, to be elucidated.

In contrast, if the redox state of magmas emitted during the build up of the Tharsis province lied at the upper end of the redox range recorded by Shergottites and/or if those magmas were hydrous, then most of the dissolved sulfur prior to eruption was degassed. Our calculations show that if such magmas were oxidized and dry $\left(0.05 \mathrm{wt} . \% \mathrm{H}_{2} \mathrm{O}\right)$, they degassed $\sim 2000$ $3000 \mathrm{ppm} \mathrm{S}$ and such volcanic gases were dominated by sulfur species $(\sim 50 \mathrm{~mol} \%)$. Half of the sulfur species injected into the martian atmosphere was $\mathrm{SO}_{2}$, the rest was $\mathrm{S}_{2}$. If such oxidized basalts were in addition hydrous, then nearly all of their sulfur was degassed (4000$7000 \mathrm{ppm}$ ) but the S-content in such gases was $\sim 20 \mathrm{~mol} \%$. The dominant sulfur species in the gas would be $\mathrm{SO}_{2}$.

Assuming that the Tharsis volcanic province produced $3 \times 10^{8} \mathrm{~km}^{3}$ of basalts (Phillips et al., 2001), we estimate that in the most favorable case (hydrous and oxidized basalts containing 7000 ppm S), about $5.4 \times 10^{21}$ gr of sulfur was degassed in the atmosphere, with $\sim 60 \%$ as $\mathrm{SO}_{2}$. Considering that nearly all atmospheric sulfur would ultimately fall back on the ground, this would yield a $60 \mathrm{~m}$ thick layer of sulfates if uniformly distributed over Mars surface (for simplicity, we considered here only anhydrite but clearly other sulfate phases would be present; King et al., 2004). Such large quantities of sulfates in the martian regolith are in line with the suggestion that some deposits that are on the order of a few hundred meters thick with up to 20 to $30 \%$ sulfates (Johnson et al., 2008). If only $2500 \mathrm{ppm} \mathrm{S}$ were degassed by the $3.10^{8} \mathrm{~km}^{3}$ of basalts, an equivalent layer of $25 \mathrm{~m}$ of sulfates covering the martian surface could be formed.

Degassing of volcanic sulfur therefore provides an explanation to the high content of this element in the martian regolith. Furthermore, since volcanic $\mathrm{SO}_{2}$ is readily scrubbed out from volcanic gases by aquifers (Symonds et al., 2001), this, along with high bulk S contents of the gas phase, may have lead to extensive acidification of any persistent layer of water on Mars (Halevy et al., 2007). An important consequence of such a scenario would be the inhibition of carbonate precipitation and/or the dissolution of pre-existing surface carbonates in seawater ([Fairen et al., 2004] and [Halevy et al., 2007]), which in turn would have favored the preservation of high $\mathrm{CO}_{2}$ content in the atmosphere (Halevy et al., 2007).

\section{Perspectives}

On a larger scale, our modeling has also implications for the understanding of sulfur systematics in the Solar system. For instance, as stressed above, Aubrites rank among the 
most reduced achondrites (Righter et al., 2007), and have very high sulfur contents in their mesostase (Fogel, 2005), both features being in qualitative agreement with our model predictions (Fig. 1). Such an intimate relationships between accretion $f \mathrm{O}_{2}$ and $\mathrm{S}$ also holds true for Vesta, whose FeO and S ([Righter et al., 2007] and [Gibson et al., 1985]) contents fall close to our calculated curve (Fig. 1). That the $\mathrm{S}$ and FeO contents of Aubrites, Earth, Mars and Vesta can be reproduced by one single model is circumstantial evidence for the strong, yet highly non linear, interrelationships existing between $\mathrm{S}$ and $\mathrm{fO}_{2}$ in the Solar system (Fig. 1). It indicates that, asides from bulk sulfur, $\mathrm{fO}_{2}$ variations among planets or planetesimals, either during accretion or at later stages (Rubie et al., 2004), will largely control the amount of S outgassed, whenever magmatism takes place. Any planetary body having a bulk redox state ( $\mathrm{Fe} / \mathrm{FeO}$ ratio) different from either Earth or Mars will have a different style of sulfur degassing. Jupiter's satellite Io, the most volcanically active planetary body of the solar system, is frequently emitting large quantities of sulfur as $\mathrm{SO}_{2} \pm \mathrm{S}_{2}$ (Zolotov and Fegley, 1999) which possibly mirror one of the extreme cases simulated in the previous sections. On the other side, Mercury's mantle, whose FeO content is estimated to be in the range $0-3 \mathrm{wt} . \%$ (Righter et al., 2007), should have a higher mantle S content than Earth (for a similar bulk S content), similar to that of Aubrite meteorites (Fig. 1). The degassing systematic of magmas produced from such an S-rich mantle would perhaps mimic the one we exemplify here for Mars given the tenuous atmosphere that was likely prevailing on early Mercury.

\section{Acknowledgments}

This work was funded by the French program on Planetology (PNP-2007, project "MagMars"). We acknowledge the careful reviews of Penelope King and Marc Hirschmann and the editorial handling of Richard Carlson.

\section{References}

Allègre et al., 2001 C.J. Allègre, G. Manhès and E. Lewin, Chemical composition of the Earth and the volatility control on planetary genetics, Earth and Planetary Science Letters 185 (2001), pp. 49-69

Barabash et al., 2007 S. Barabash, A. Fedorov, R. Lundin and J.-A. Sauvaud, Martian atmospheric erosion rates, Science 315 (2007), pp. 501-503.

Behrens and Gaillard, 2006 H. Behrens and F. Gaillard, Geochemical aspects of melts: volatiles and redox behavior, Elements 2 (2006), pp. 275-280

Bullock and Moore, 2007 M.A. Bullock and J.M. Moore, Atmospheric conditions on early Mars and the missing layered carbonates, Geophysical Research Letters 34 (2007), p. L19201

Burgisser and Scaillet, 2007 A. Burgisser and B. Scaillet, Redox evolution of a degassing magma rising to the surface, Nature 445 (2007), pp. 194-197

Carroll and Webster, 1994 M. Carroll and J.D. Webster, Solubilities of sulfur, noble gases, nitrogen, chlorine and fluorine in magmas. In: M.R. Carroll and J.R. Holloway, Editors, Volatiles in Magmas, Reviews in Mineralogy vol. 30 (1994), pp. 231-280.

Cartigny et al., 2008 P. Cartigny, F. Pineau, C. Aubaud and M. Javoy, Towards a consistent mantle carbon flux estimate: insights from volatile systematics $\left(\mathrm{H}_{2} \mathrm{O} / \mathrm{Ce}, \delta \mathrm{D}, \mathrm{CO}_{2} / \mathrm{Nb}\right)$ in the 
North Atlantic mantle $\left(14^{\circ} \mathrm{N}\right.$ and $\left.34^{\circ} \mathrm{N}\right)$, Earth and Planetary Science Letters 265 (2008), pp. 672-685.

Clark and Baird, 1979 B.C. Clark and A.K. Baird, Is the martian lithosphere sulfur rich?, Journal of Geophysical Research 84 (1979), pp. 8395-8403.

Chabot, 2004 N.L. Chabot, Sulfur contents of the parental metallic cores of magmatic iron meteorites, Geochimica et Cosmochimica Acta 68 (2004), pp. 3607-3618.

Dreibus and Palme, 1996 G. Dreibus and H. Palme, Cosmochemical constraints on the sulfur content in the Earth's core, Geochimica and Cosmochimica Acta 60 (1996), pp. 1125-1130.

Elkins-Tanton, 2008 L.T. Elkins-Tanton, Linked magma ocean solidification and atmospheric growth for Earth and Mars, Earth and Planetary Science Letters 271 (1-4) (2008), pp. 181191

Elkins-Tanton et al., 2005 L.T. Elkins-Tanton, E.M. Parmentier and P.C. Hess, The formation of ancient crust on Mars through magma ocean processes, Journal of Geophysical Research 110 (2005), p. E12S01

Fairen et al., 2004 A.G. Fairen, D. Fernandez-Remolar, J.M. Dohm, V.R. Baker and R. Amils, Inhibition of carbonate synthesis in acidic oceans on early Mars, Nature 431 (2004), pp. 423426.

Farquhar et al., 2000 J. Farquhar, J. Savrino, T.L. Jackson and M.H. Thiemens, Evidence of atmospheric sulphur in the martian regolith from sulphur isotopes in meteorites, Nature $\mathbf{4 0 4}$ (2000), pp. 50-52

Fogel, 2005 R.A. Fogel, Aubrite basalt vitrophyres: the missing basaltic component and highsulfur silicate melts, Geochimica et Cosmochimica Acta 69 (2005), pp. 1633-1648.

Gaillard et al., 2003 F. Gaillard, M. Pichavant and B. Scaillet, Experimental determination of activities of $\mathrm{FeO}$ and $\mathrm{Fe}_{2} \mathrm{O}_{3}$ components in hydrous silicic melts under oxidizing conditions, Geochimica et Cosmochimica Acta 67 (2003), pp. 4389-4409.

Gaillard et al., 2008 F. Gaillard, M. Malki, G. Iacono-Marziano, M. Pichavant and B. Scaillet, Carbonatite melts and electrical conductivity of the asthenosphere, Science 322 (2008), pp. $1363-1365$.

Gendrin et al., 2005 A. Gendrin, N. Mangold, J.P. Bibring, Y. Langevin, B. Gondet, F. Poulet, G. Bonello, C. Quantin, J. Mustard, R. Arvidson and S. LeMouélic, Sulfates in martian layered terrains: the OMEGA/Mars Express view, Science 307 (2005), pp. 1587-1591.

Gibson et al., 1985 E.K. Gibson, C.B. Moore, T.M. Primus and C.F. Lewis, Sulfur in achondritic meteorites, Meteoritics 20 (1985), pp. 503-511.

Halevy et al., 2007 I. Halevy, M. Zuber and D. Schrag, A sulfur dioxide climate feedback on early Mars, Science 318 (2007), pp. 1903-1907 
Herd, 2003 C.D.K. Herd, The oxygen fugacity of olivine-phyric martian basalts and the components within the mantle and crust of Mars, Meteoritics \& Planetary Science 38 (2003), pp. 1793-1805.

Herd et al., 2002 C.D.K. Herd, L.E. Borg, J.H. Jones and J.J. Papike, Oxygen fugacity and geochemical variations in the martian basalts: implications for martian basalt petrogenesis and the oxidation state of the upper mantle of Mars, Geochimica et Cosmochimica Acta 66 (11) (2002), pp. 2025-2036.

Herd et al., 2005 C.D.K. Herd, A.H. Treiman, G.A. McKay and C.K. Shearer, Light lithophile elements in martian basalts: evaluating the evidence for magmatic water degassing,

Geochimica et Cosmochimica Acta 69 (2005), pp. 2431-2440

Hilgren et al., 2000 V.J. Hilgren, C.K. Gessmann and J. Li, An experimental perspective on light elements in the Earth's core. In: R.M. Canup and K. Righter, Editors, Origin of the Earth and Moon, The university of Arizona Press (2000), pp. 245-264.

Hirschmann and Withers, 2008 M.M. Hirschmann and A.C. Withers, Ventilation of $\mathrm{CO}_{2}$ from a reduced mantle and consequences for the early martian greenhouse, Earth and Planetary Science Letters 270 (2008), pp. 147-155.

Holloway, 1987 J.R. Holloway, Igneous fluids. In: H.P. Eugster and I.S.E. Carmichael, Editors, Thermodynamic Modelling of Geological Materials: Minerals, Fluids, Melts, Reviews in Mineralogy vol. 17 (1987), pp. 211-233.

Holzheid and Grove, 2002 A. Holzheid and T.L. Grove, Sulfur saturation limits in silicate melts and their implications for core formation scenarios for terrestrial planets, American Mineralogist 87 (2002), pp. 227-237.

Ikoma and Genda, 2006 M. Ikoma and I. Genda, Constraints on the mass of a habitable planet with water of nebular origin, Astrophysical Journal 648 (2006), pp. 696-706.

Johnson et al., 2008 S.S. Johnson, M.A. Mischna, T.L. Grove and M.T. Zuber, Sulfur-induced greenhouse warming on early Mars, Journal of Geophysical Research 113 (2008), p. E08005

Kilburn and Wood, 1997 M.R. Kilburn and B.J. Wood, Metal-silicate partitioning and the incompatibility of S and Si during core formation, Earth and Planetary Science Letters 152 (1997), pp. 139-148.

King and McSween, 2005 P.L. King and H.Y. McSween Jr., Effects of H2O, pH and oxidation state on the stability of Fe-minerals on Mars, Journal of Geophysical Research 110 (2005), p. E12S10

King et al., 2004 P.L. King, D.T. Lescinsky and H.W. Nesbitt, The composition and evolution of primordial solutions on Mars, with application to other planetary bodies, Geochimica et Cosmochimica Acta 68 (2004), pp. 4993-5008.

Knoll and Grotzinger, 2006 A.H. Knoll and J. Grotzinger, Water on Mars and the prospect of martian life, Elements 2 (2006), pp. 169-173. 
Kress, 1997 V.C. Kress, Thermochemistry of sulfide liquids. I. The system O-S-Fe at 1 bar, Contributions to Mineralogy and Petrology 127 (1997), pp. 176-186.

Kress and Carmichael, 1991 V.C. Kress and I.S.E. Carmichael, The compressibility of silicate liquids containing $\mathrm{Fe} 2 \mathrm{O} 3$ and the effect of composition, temperature, Oxygen fugacity and pressure on their redox states, Contributions to Mineralogy and Petrology 108 (1991), pp. 8292.

Li and Agee, $1996 \mathrm{~J}$. Li and C.B. Agee, Geochemistry of mantle-core differentiation at high pressure, Nature 381 (1996), pp. 686-689.

Mathez, 1979 E.A. Mathez, Sulfide relations in Hole $418 A$ flows and sulfur contents of glasses, Initial Rep. of the Deep Sea Drilling Project, 53, U.S. Gov't Printing Office, Washington, D.C. (1979), pp. 1069-1085.

Mathez, 1984 E.A. Mathez, Influence of degassing on oxidation-states of basaltic lavas, Nature 310 (1984), pp. 371-375.

Mavrogenes and O'Neill, 1999 J. Mavrogenes and H.S.C. O'Neill, The relative effects of pressure, temperature and oxygen fugacity on the solubility of sulfide in magmas, Geochimica Cosmochimica Acta 63 (1999), pp. 1173-1180

McDonough and Sun, 1995 W.F. McDonough and S.S. Sun, The composition of the Earth, Chemical Geology 120 (1995), pp. 1125-1130.

McSween, 1994 H.Y. McSween, What we have learned about Mars from SNC meteorites, Meteoritics 29 (1994), pp. 757-779.

McSween et al., 2001 H.Y. McSween, T.L. Grove, R.C. Lentz, J.C. Dann, A.H. Holzheid, L.R. Riciputi and J.G. Ryan, Geochemical evidence for magmatic water within Mars from pyroxenes in the Shergotty meteorite, Nature 409 (2001), pp. 487-490.

Monders et al., 2007 A.G. Monders, M, E. édar d and T.L. Grove, Phase equilibrium investigations of the Adirondack class basalts from the Gusev plains, Gusev crater, Mars, Meteoritics \& Planetary Science 42 (2007), pp. 131-148.

Moretti and Ottonello, 2004 R. Moretti and G. Ottonello, Solubility and speciation of sulfur in silicate melts: the Conjugated-Toop-Samis-Flood-Grjotheim (CTSFG) model, Geochimica et Cosmochimica Acta 69 (2004), pp. 801-823.

Musselwhite et al., 2006 D.S. Musselwhite, H.A. Dalton, W.S. Kiefer and A.H. Treiman, Experimental petrology of the basaltic shergottite Yamato-980459: implications for the thermal structure of the martian mantle, Meteoritics \& Planetary Science 41 (2006), pp. 1271-1290.

Niu, 1997 Y. Niu, Mantle melting and melt extraction processes beneath ocean ridges: evidence from abyssal peridotites, Journal of Petrology 38 (1997), pp. 1047-1074.

O'Neill, 1991 H.S.C. O'Neill, The origin of the moon and the early history of the Earth-I. A chemical model, Geochimica et Cosmochimica Acta 55 (1991), pp. 1159-1172. 
O'Neill and Mavrogenes, 2002 H.S.C. O'Neill and J. Mavrogenes, The sulfide saturation capacity and the sulfur content at sulfide saturation of silicate melts at $1400{ }^{\circ} \mathrm{C}$ and $1 \mathrm{bar}$, Journal of Petrology 43 (2002), pp. 1049-1087.

Palme and Jones, 2003 H. Palme and A. Jones, Solar system abundances of the elements, Treatise on geochemistry 1 (2003), pp. 41-61 ISBN: 0-08-044336-2.

Pepin, 2006 R.O. Pepin, Atmospheres on the terrestrial planets: clues to origin and evolution, Earth and Planetary Science Letters 252 (2006), pp. 1-14.

Phillips et al., 2001 R.J. Phillips, M.T. Zuber, S.C. Solomon, M.P. Golombek, B.M. Jakosky, W.B. Banerdt, D.E. Smith, R.M.E. Williams, B.M. Hynek, O. Aharonson and S.A. Hauck, Ancient geodynamics and global-scale hydrology on Mars, Science 291 (2001), pp. 25872591. K. Righter and M.J. Drake, Core formation in Earth's moon, Mars, and Vesta, Icarus 124 (1996), pp. 513-529.

Righter et al., 2007 K. Righter, M.J. Drake and E. Scott, Compositional relationships between meteorites and terrestrial planets. In: D. Lauretta, L. Leshin and H.Y. McSween, Editors, Meteorites and the Early Solar System II, Univ. Arizona Press, Tucson (2007).

Rubie et al., 2004 D.C. Rubie, C.K. Gessmann and D.J. Frost, Partitioning of oxygen during core formation on the Earth and Mars, Nature 429 (2004), pp. 58-61.

Saal et al., 2002 A.E. Saal, E.H. Hauri, C.H. Langmuir and M.R. Perfit, Vapour undersaturation in primitive mid-ocean-ridge basalt and the volatile content of Earth's upper mantle, Nature 419 (2002), pp. 451-455.

Scaillet and Pichavant, 2004 B. Scaillet and M. Pichavant, Role of $\mathrm{fO}_{2}$ in fluid saturation of oceanic basalt, Nature 430 (2004)

Scaillet and McDonald, 2006 B. Scaillet and R. McDonald, Experimental and thermodynamic constraints on the sulphur yield of peralkaline and metaluminous silicic flood eruptions, Journal of Petrology 47 (7) (2006), pp. 1413-1437

Scaillet et al., 2003 B. Scaillet, J.F. Luhr and M.R. Carroll, Petrological and volcanological constraints on volcanic sulfur emissions to the atmosphere. In: A. Robock and C. Oppenheimer, Editors, Volcanism and the Earth's Atmosphere, AGU Geophysical monograph vol. 139 (2003), pp. 11-40.

Sherman, 1997 D.M. Sherman, The composition of the Earth's core: constraints on S and Si vs temperature, Earth and Planetary Science Letters 153 (1997), pp. 149-155.

Stewart et al., 2007 A.J. Stewart, M.W. Schmidt, W. Van-Westrenen and C. Liebske, Mars: a new core-crystallization regime, Science 316 (2007), pp. 1323-1325.

Symonds et al., 1994 R.B. Symonds, W.I. Rose, G.J.S. Bluth and T.M. Gerlach, Volcanic-gas studies: methods, results, and applications. In: M.R. Carroll and J.R. Holloway, Editors, Volatiles in Magmas, Reviews in Mineralogy vol. 30 (1994), pp. 1-66. 
Symonds et al., 2001 R.B. Symonds, T.M. Gerlach and M.H. Reed, Magmatic gas scrubbing: implications for volcano monitoring, Journal of Volcanology and Geothermal Research 108 (2001), pp. 303-341.

Wadhwa, 2001 M. Wadhwa, Redox states of Mars' upper mantle and crust from Eu anomalies in shergottite pyroxenes, Science 291 (2001), pp. 1527-1530

Wallace and Carmichael, 1992 P.J. Wallace and I.S.E. Carmichael, Sulfur in basaltic magmas, Geochimica Cosmochimica Acta 56 (1992), pp. 1863-1874.

Wang et al., 1991 C. Wang, J. Hirama, T. Nagasaka and S. Ban-Ya, Phase equilibria of liquid Fe-S-C ternary, ISIJ International 11 (1991), pp. 1292-1299.

Wänke and Dreibus, 1994 H. Wänke and G. Dreibus, Chemistry and accretion history of Mars, Phil. Trans. Royal Soc. London A 359 (1994), pp. 285-293. B.J. Wood, M.J. Walther and J. Wade, Accretion of the Earth and segregation of its core, Nature 441 (2006), pp. 825833.

Yen, 2005 R.G. Yen et al., An integrated view of the chemistry and mineralogy of martian soils, Nature 436 (2005), pp. 49-54.

Zipfel et al., 2000 J. Zipfel, P. Scherer, B. Spettel, G. Dreibus and L. Schultz, Petrology and chemistry of the new shergottite Dar al Gani 476, Meteoritics \& Planetray Science 35 (2000), pp. 95-106.

Zolotov and Fegley, 1999 M.Y. Zolotov and B. Fegley Jr., Oxidation state of volcanic gases and the interior of Io, Icarus 141 (1999), pp. 40-52. 


\section{Figures}

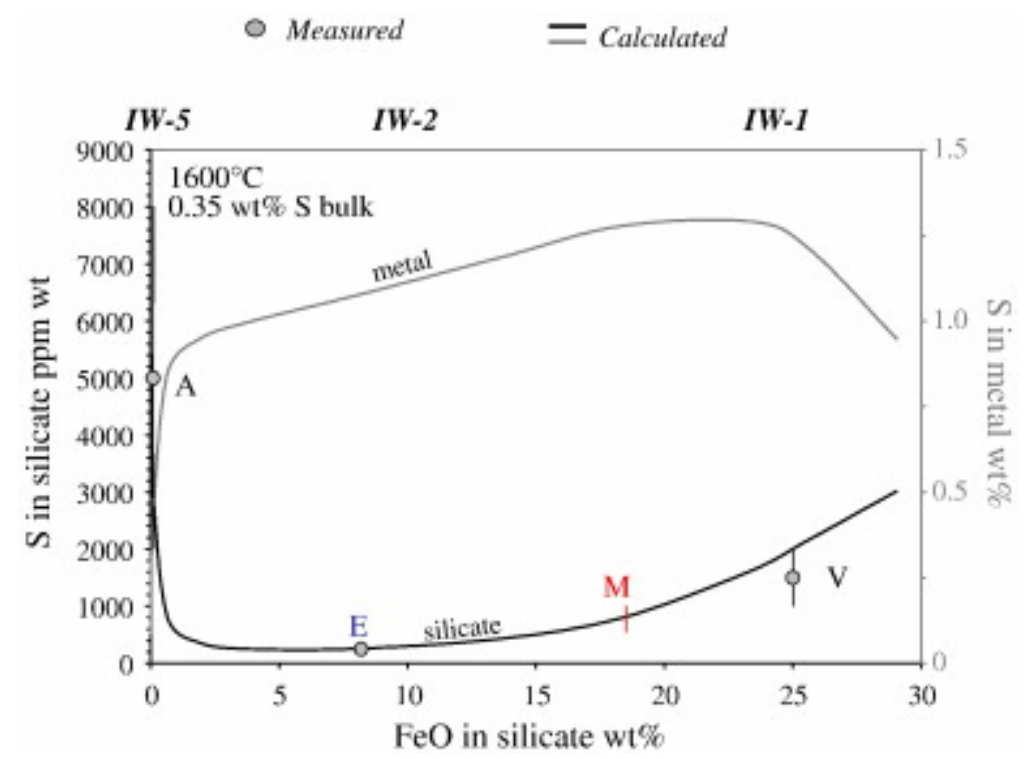

Fig. 1. Evolution of the sulfur content of the coexisting silicate and metal melts with the FeO content of the silicate melt, calculated for a bulk chondritic composition having a bulk sulfur content of $0.35 \mathrm{wt} . \%$. Corresponding values of oxygen fugacity relative to the iron-wustite buffer are given on top of the diagram. Points refer to measured/estimated FeO-S content in the silicate portion (mantle) of several planetary bodies. A refers to Aubrite meteorites, E to Earth, and V to Vesta. The inferred sulfur contents of Earth is taken from McDonough and Sun (1995), those of aubrite meteorites are from Fogel (2005) and Vesta asteroid from Gibson et al. (1985). The FeO contents of the silicate part of planetary and asteroidal bodies are taken from Righter et al. (2007). We estimate the S-content of the martian mantle at 600-900 ppm (red bar, M). (For interpretation of the references to colour in this figure legend, the reader is referred to the web version of this article.) 


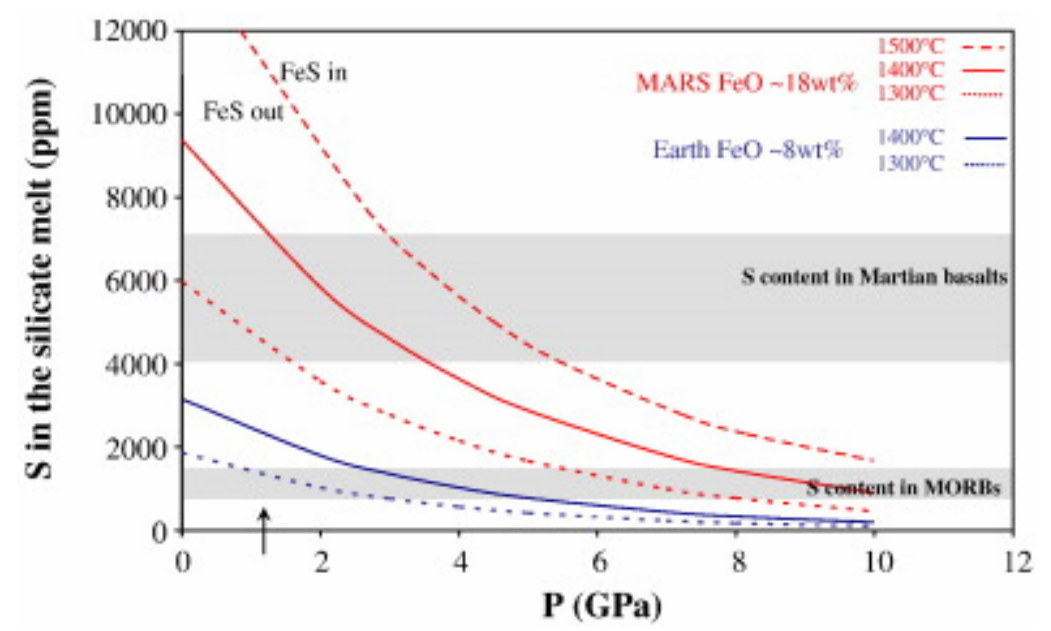

Fig. 2. Pressure effect on the sulfur content of sulfide-saturated basalt melts, for iron-rich $(\mathrm{FeO}=18$ wt.\%, Mars $)$ and iron-poor $(\mathrm{FeO}=8$ wt.\%, Earth $)$ compositions. Calculations were performed combining data of Mavrogenes and O'Neill (1999) and O'Neill and Mavrogenes (2002), following Holzheid and Grove (2002). Calculations are shown for $1300{ }^{\circ} \mathrm{C}, 1400{ }^{\circ} \mathrm{C}$, and $1500{ }^{\circ} \mathrm{C}$. Also shown is the range of sulfur contents of martian basalts inferred from this study and the one of Earth basalts (MORBs). The arrow at $1.2 \mathrm{GPa}$ indicates the pressure of magma extraction on Mars, as inferred from experimental petrology ([Musselwhite et al., 2006] and [Monders et al., 2007]). 


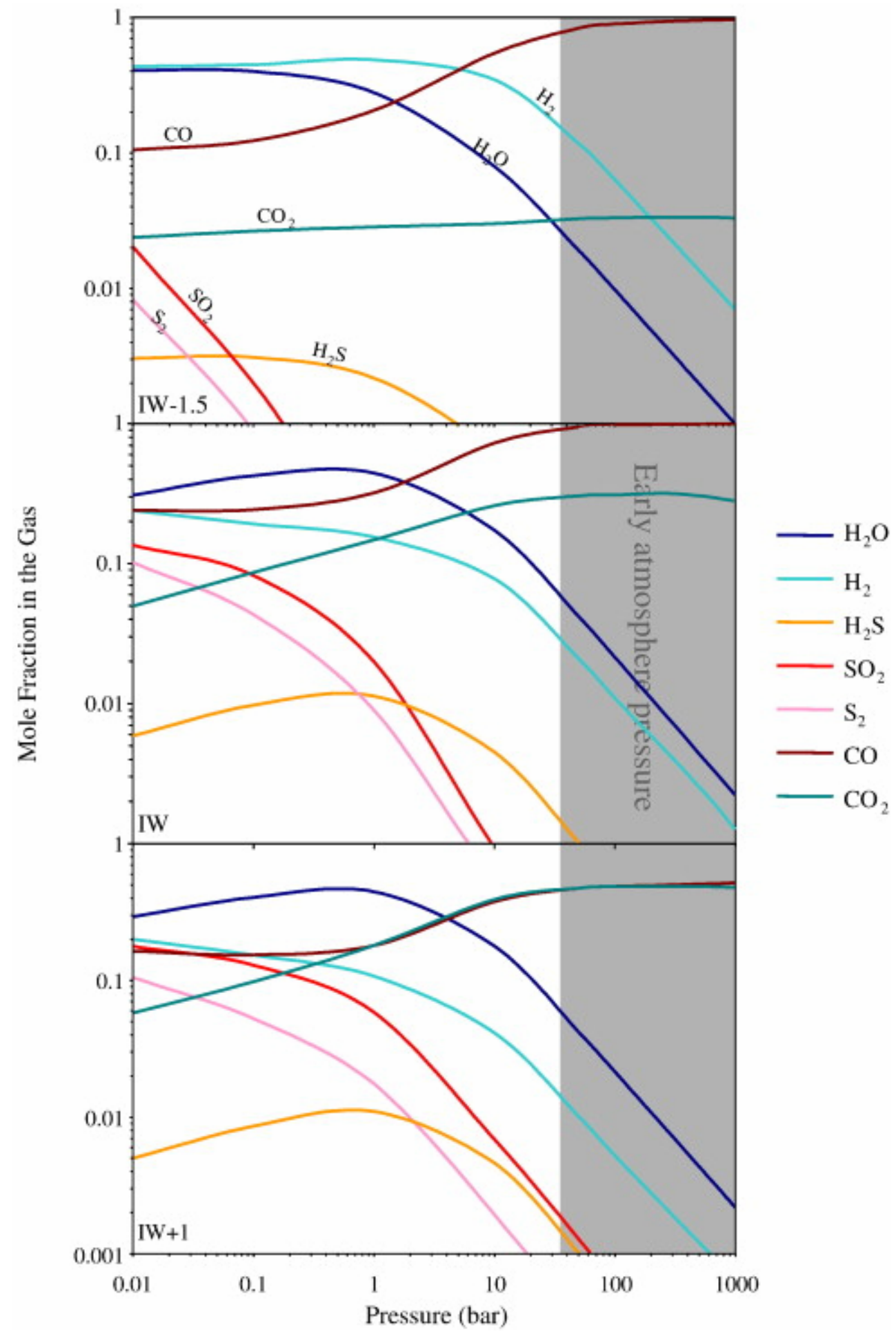

Fig. 3. Composition (mole fractions calculated in the system $\mathrm{COHS}+\mathrm{FeO}_{x}$ ) of gases emitted by a hypothetical martian magma ocean as a function of pressure. The gas is in equilibrium with a basalt containing $900 \mathrm{ppm} \mathrm{S}, 0.1$ wt.\% $\mathrm{H}_{2} \mathrm{O}, 10-700$ ppm $\mathrm{CO}_{2}$ (see Hirschmann and Withers, 2008) at various $\mathrm{fO}_{2}(\mathrm{IW}-1.5, \mathrm{IW}, \mathrm{IW}+1)$. The horizontal grey bar defines the possible range of atmospheric pressures on early Mars after Elkins-Tanton, 2008 L.T. ElkinsTanton, Linked magma ocean solidification and atmospheric growth for Earth and Mars, Earth and Planetary Science Letters 271 (1-4) (2008), pp. 181-191 


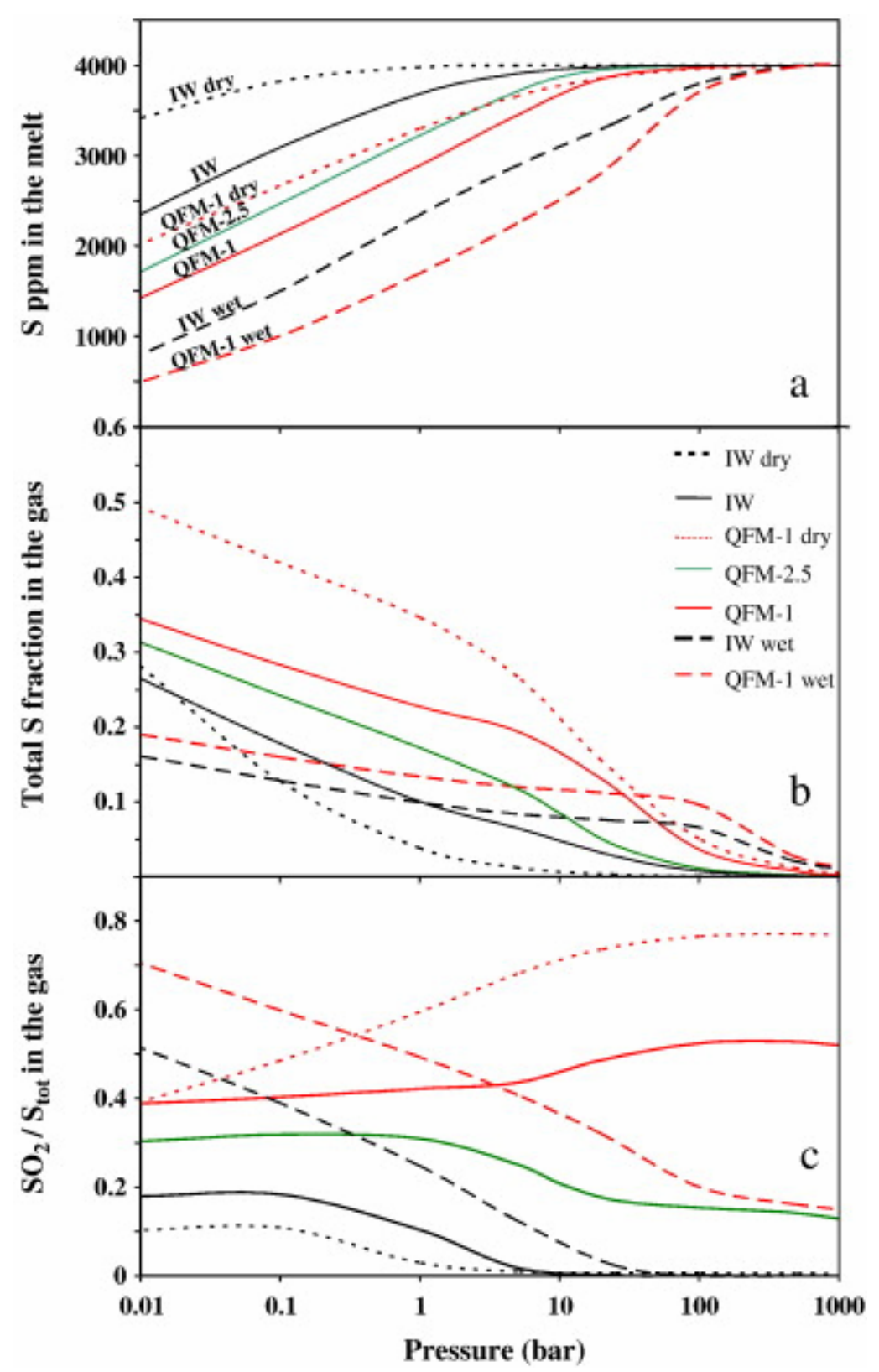

Fig. 4. Calculated degassing paths for martian basalts as a function of pressure, for different redox conditions and water contents. In all cases, basalts contain $4000 \mathrm{ppm}$ S. Full lines show the degassing of basalts with 0.2 wt. $\%$ dissolved water, at different $\mathrm{fO}_{2}$ (black: reduced, green: intermediate, red: oxidized). Dashed lines show dry (0.05 wt.\% water, small dashes) and wet ( $0.8 \mathrm{wt} . \%$ water, large dashes) basalts for reduced and oxidized conditions (same color codes as above). (a) Sulfur content in the basalt during degassing. (b) Total sulfur content in the gas expressed in $\mathrm{mol} \%\left(\mathrm{~S}_{\text {tot }}=\mathrm{H}_{2} \mathrm{~S}+\mathrm{S}_{2}+\mathrm{SO}_{2}\right)$. (c) Fraction of sulfur in the $\mathrm{SO}_{2}$ form: $\mathrm{SO}_{2} /\left(\mathrm{S}_{\text {tot }}\right)$. 


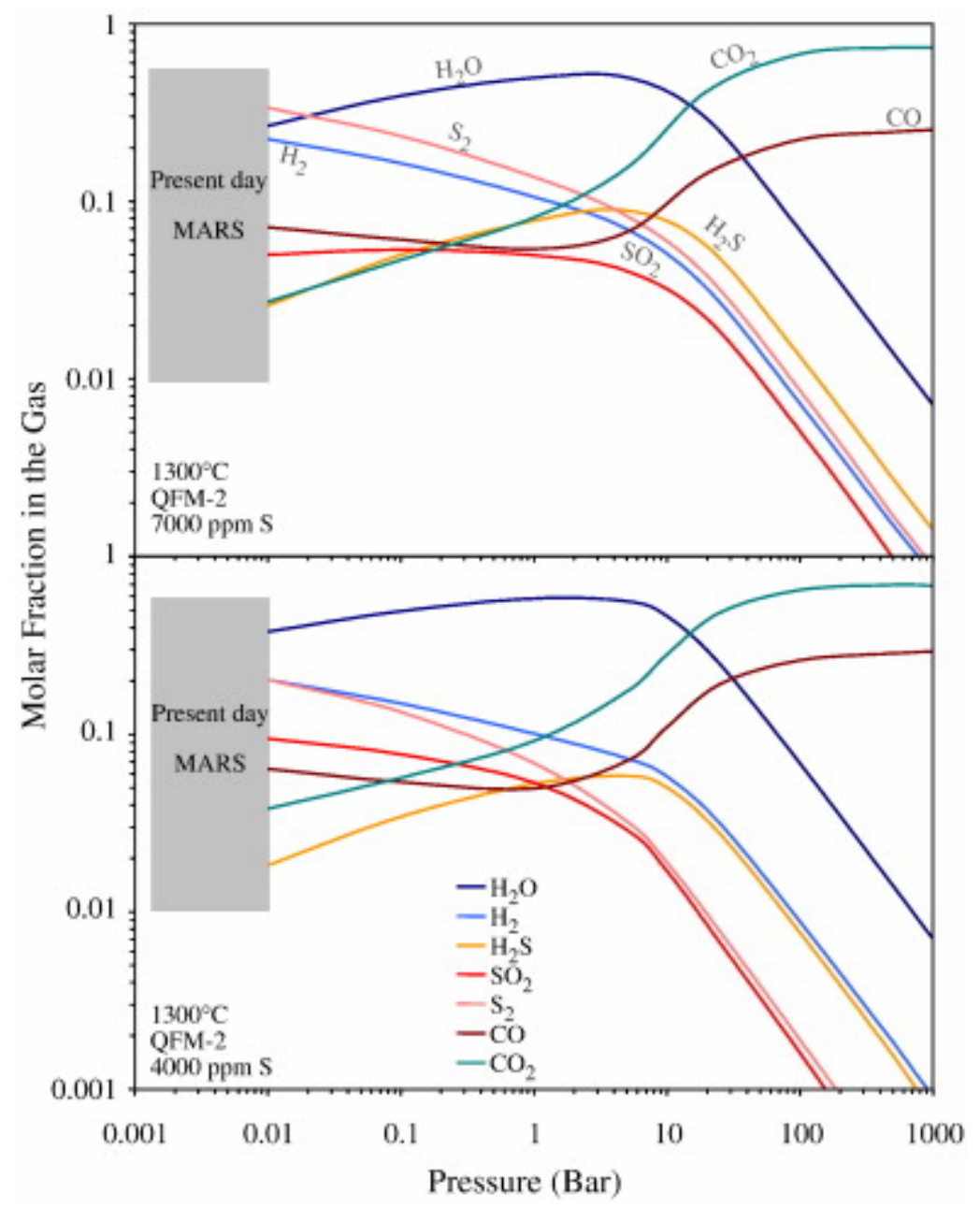

Fig. 5. Composition of the volcanic gas phase as a function pressure for typical martian basalts. Both panels show calculations for basalts containing $0.2 \mathrm{wt} \% \%$ water, and 500 $600 \mathrm{ppm} \mathrm{CO}_{2}$ at $\mathrm{fO}_{2}$ of QFM-2. The top panel shows a basalt with $7000 \mathrm{ppm} \mathrm{S}$ and the bottom one shows a basalt with 4000 ppm S (see Fig. 2 for justification of S contents). 
Table 1. : Compilation of sulfur abundance in chondrites and planetary bodies (see text for references)

\begin{tabular}{|c|c|c|c|c|}
\hline Sample & Origin & $\begin{array}{l}\text { FeO } \\
\text { wt. \% }\end{array}$ & S-bearing phase & S wt.\% \\
\hline \multicolumn{5}{|c|}{ Chondrites, non differentiated bodies } \\
\hline Enstatite chondrite & & $0.1-1$ & $\begin{array}{l}\mathrm{FeS},(\mathrm{Mg}-\mathrm{Mn}-\mathrm{FeS}) \\
(\mathrm{CaS})\end{array}$ & $5-10$ \\
\hline Ordinary chondrite & & $6-15$ & $\mathrm{FeS}$ & $2-3$ \\
\hline $\begin{array}{l}\text { Carbonaceous I } \\
\text { chondrite }\end{array}$ & & 23 & $\mathrm{FeS}$ & $5-6$ \\
\hline \multicolumn{5}{|c|}{ A-Chondrites, differentiated bodies } \\
\hline Iron meteorites & $\begin{array}{l}\text { Core of asteroidal } \\
\text { bodies }\end{array}$ & 0 & Fe-metal & $1-14$ \\
\hline \multirow[t]{2}{*}{ Aubrites } & Enstatite Ch. & $0.1-1$ & $\mathrm{FeS}$ & $0.2-0.8$ \\
\hline & & & Glass & 2.5 \\
\hline MORB & Earth & 8 & Basalt & 0.08 \\
\hline Shergottites & Mars & $17-20$ & Basalt & $0.4-0.7$ \\
\hline \multicolumn{5}{|c|}{ Planetary material, mantle and core } \\
\hline Earth mantle & Earth magma ocean & 8 & $\mathrm{FeS}$ & 0.025 \\
\hline Martian mantle & Mars magma ocean & $19-20$ & $\mathrm{FeS}$ & $\begin{array}{l}0.06- \\
0.09\end{array}$ \\
\hline Earth core & & $0-10$ & Fe-metal & $2-8$ \\
\hline Martian core & & 0 & Fe-metal & $3-18$ \\
\hline
\end{tabular}

